\title{
Value of repeat biopsy in lupus nephritis flares
}

\author{
G Greloni, ${ }^{1}$ M Scolnik, ${ }^{2,3} \mathrm{~J}$ Marin, ${ }^{2,3}$ E Lancioni, ${ }^{2,3}$ C Quiroz, ${ }^{2,3} \mathrm{~J}$ Zacariaz, ${ }^{2,3}$ \\ $\mathrm{P}$ De la Iglesia Niveyro, ${ }^{4} \mathrm{~S}$ Christiansen, ${ }^{4} \mathrm{M}$ A Pierangelo, ${ }^{1} \mathrm{C}$ F Varela, ${ }^{1}$ \\ G J Rosa-Diez, ${ }^{1}$ L J Catoggio, ${ }^{2,3}$ E R Soriano ${ }^{2,3}$
}

To cite: Greloni G, Scolnik M, Marin J, et al. Value of repeat biopsy in lupus nephritis flares. Lupus Science \& Medicine 2014;1:e00004. doi:10.1136/lupus-2013000004

Received 18 December 2013 Revised 26 December 2013 Accepted 30 December 2013

\section{(a) CrossMark}

${ }^{1}$ Nephrology Service, Hospital Italiano de Buenos Aires, Buenos Aires, Argentina ${ }^{2}$ Rheumatology Section, Medical Services, Hospital Italiano de Buenos Aires, Buenos Aires, Argentina ${ }^{3}$ Instituto Universitario Escuela de Medicina Hospital Italiano de Buenos Aires, Fundacion Dr. Pedro M Catoggio para el Progreso de la Reumatologia, Buenos Aires, Argentina

${ }^{4}$ Pathology Department, Hospital Italiano de Buenos Aires, Buenos Aires, Argentina

Correspondence to Professor Enrique R Soriano; enrique.soriano@ hospitalitaliano.org.ar

\section{ABSTRACT}

Objectives: Renal flares are common in lupus nephritis (LN), and class switch is thought to be characteristic. There is no agreement on indications for performing a repeat renal biopsy. Our objective was to retrospectively review patients who had more than one renal biopsy performed on clinical indications, and analyse clinical, pathological and treatment changes after successive biopsies.

Methods: Forty-five patients with LN and one or more repeat renal biopsies were included, with a total of 116 biopsies.

Results: Of the 71 repeat biopsies, pathological transition occurred in $39(54.9 \%)$. When having a previous biopsy with a proliferative lesion, class switch occurred in $55.6 \%$, with $24.4 \%$ evolving into nonproliferative classes. When previous biopsy was class $\mathrm{V}$, transition to other classes occurred in $58.3 \%$ and changes were all into proliferative classes. Conversion from one pure proliferative form to another (class III to class IV or vice versa) happened in $11.3 \%$ of the rebiopsies, with 62 rebiopsies (87.3\%) leading to a change in the treatment regimen.

Conclusions: Histological transformations were common, and they occurred when the previous biopsy had non-proliferative lesions as well as when lesions were proliferative. Treatments were modified after repeat renal biopsy in the majority of patients. In this experience, kidney repeat biopsies were useful in guiding treatment of $L N$ flares.

\section{INTRODUCTION}

Renal biopsy has a paramount role in the diagnosis of lupus nephritis (LN). Histologic findings provide the basis for treatment recommendations. Flares represent a significant problem because of the potential for cumulative damage that may lead to deterioration of renal function even after a successful treatment. ${ }^{1}{ }^{2}$ The pathological class of LN may change to a different class during a disease flare.

The clinical relevance of the repeat renal biopsy remains in debate. Some authors

\section{KEY MESSAGES}

- This paper deals with the importance of repeating renal biopsies in lupus nephritis (LN) flares.

- Class changes in LN flares are frequent and not predictable by the clinical picture. Renal rebiopsy may provide a better understanding of the kidney damage and guide treatment decisions.

- A strength of this study is the important number of renal rebiopsies performed under clinical judgment and with long follow up. A limitation is retrospective analysis; some missing information and biopsies evaluated by different pathologists.

suggest performing it after induction or maintenance treatment in order to assess treatment efficacy. ${ }^{3}{ }^{4}$ Others propose a repeat biopsy only on clinical indications (worsening of renal function, persistent proteinuria or haematuria, suspicion of renal flare or class change, etc). ${ }^{1256}$ Even in this setting, the importance of a second biopsy may not be uniform, since some authors have proposed that patients with proliferative lesions on their original biopsy rarely switch to a pure non-proliferative nephritis during a flare, and in these cases, appropriate induction treatment can be initiated without additional biopsies. $^{7}$

Some features in the second renal biopsy have been associated with bad renal prognosis: persisting inflammatory lesions at 6 months of treatment, ${ }^{8}$ the presence of subendothelial deposits after 2 years of treatment $^{1}$ and higher chronicity indexes. ${ }^{2}{ }^{9}$ These findings suggest that repeat biopsies could have a prognostic value besides the immediate clinical relevance in taking therapeutic decisions.

Our objective was to retrospectively review patients who had more than one renal biopsy performed on clinical indications and analyse clinical, pathological and treatment changes after successive biopsies. 


\section{METHODS}

Patients

Patients were recruited at the Hospital Italiano de Buenos Aires, Argentina. Systemic lupus erythematosus patients (fulfilling American College of Rheumatology $(\mathrm{ACR})^{10}$ or The Systemic Lupus International Collaborating Clinics (SLICC) ${ }^{11}$ criteria) who had a diagnosis of $\mathrm{LN}$ and two or more renal biopsies after year 2001 were included. Electronic medical records were reviewed and clinical, laboratory and treatment data were obtained from each patient.

Laboratory values, such as serum creatinine, albumin, urea, proteinuria, complement levels (C3 and C4), antidouble-stranded DNA antibody (anti-dsDNA) titre, were selected during the month before and the month after the renal biopsy was performed. Antibodies were detected by the hospital laboratory using standard methods: indirect immunofluorescence for antinuclear antibodies on HEp 2 cells, immunofluorescence on crithidia luciliae for anti-dsDNA antibodies, ELISA for Sm antibodies, anticardiolipin antibodies, antibeta2glicoprotein I antibodies and lupus anticoagulant test according to the International Society of Thrombosis and Haemostasis (ISTH) guidelines. ${ }^{12}$ Patients were considered to have antiphospholipid syndrome if fulfilling modified Sapporo criteria (2006). ${ }^{13}$

Follow-up time was calculated since first renal biopsy until last hospital visit.

\section{Renal biopsy}

Renal biopsy was performed on clinical indications: improvement of renal disease but persistence of nonnephrotic proteinuria and/or haematuria, persistence of or relapsing nephrotic syndrome or worsening of renal function. No patients were scheduled to receive the renal biopsy to assess the efficacy of treatment.

All biopsies were assessed by experienced pathologists by light microscopy and immunofluorescence.

Renal biopsy was evaluated according to the WHO classification of $\mathrm{LN}^{14}$ when the biopsy was performed before the year 2003, and according to the international society of nephology/Renal Pathology Society (ISN/ RPS) classification of $\mathrm{LN}^{15}$ after that date. If biopsy specimens were classified according to WHO classification (class I, normal, class II, mesangial proliferation, class III, focal and segmental proliferative glomerulonephritis, class IV, diffuse proliferative glomerulonephritis, class V, membranous glomerulonephritis and class VI, sclerosing glomerulonephritis), they were reassessed according to the ISN/RPS classifications, and the new classification was compared between successive biopsies.

Activity and chronicity indices were scored according to the 1983 proposal by Austin et al. ${ }^{16}$ Class III, Class IV and combinations between III/IV plus V were considered proliferative classes. All the rest were considered non- proliferative.

\section{Treatment}

The choices of treatment regimens were up to the individual nephrologist and rheumatologist. We considered a treatment change when the immunosuppressive treatment was modified after the renal biopsy (drug change, drug addition, drug suspension).

\section{Statistical analysis}

Data were analysed using SPSS V.20.0 version for Windows. The continuous variables were presented as the mean $\pm \mathrm{SD}$, or the median and IQRs where appropriate. Categorical variables are presented as percentages. For the univariate analysis we compared two groups using Student t test when normally distributed, and Mann-Whitney test when not. Two-sided $\mathrm{p}$ values $<0.05$ were considered statistically significant.

Cox regression analysis was performed using poor outcome as dependent variable and adjusting by age, activity and chronicity indexes, and creatinine levels.

Receiver operating characteristics (ROC) curves were used to determine the best cut-off points to predict adverse outcomes.

\section{Ethical approval}

We received confirmation from our ethical committee that ethics approval was not required for this retrospective study.

\section{RESULTS}

We identified 45 lupus patients (40 women) with at least two renal biopsies. These patients had a total of 116 biopsies. Clinical characteristics of the patients are provided in table 1.

Regarding histopathological analysis, proliferative classes were the most frequent $(56.9 \%)$, followed by class V (16.4\%) (table 2).

Clinical indications for biopsies were persistent nonnephrotic proteinuria and/or haematuria $(n=59$, $50.9 \%)$, persistence of or relapsing nephrotic syndrome $(\mathrm{n}=30,25.9 \%)$, and worsening of renal function $(\mathrm{n}=21$, $18.1 \%)$. We do not have data on the cause that motivated rebiopsy in the remaining six cases.

Of the 71 repeat biopsies, pathological transition occurred related to the previous biopsy in 39 (54.9\%) and did not occur in $26(36.6 \%)$ (table 3 ).We could not assess change in six of the rebiopsies because of unknown previous biopsies.

When the previous biopsies were classified as proliferative (class III, IV or combinations between III/IV+V) $(\mathrm{n}=45)$, histological change occurred in $25(55.6 \%)$, and 11 of them changed to non-proliferative classes $(24.4 \%)$. When previous biopsy was class $\mathrm{V}(\mathrm{n}=12)$, transition to other classes occurred in seven $(58.3 \%)$, and all changed to proliferative classes. Conversion from one pure proliferative form to another (class III to class IV or vice versa) occurred in eight of the repeat biopsies (11.3\%). 
Table 1 Characteristics of lupus patients with more than one kidney biopsy during follow-up

\begin{tabular}{|c|c|}
\hline & $\begin{array}{l}\text { Lupus patients } \\
\text { with at least } 2 \\
\text { renal biopsies } \\
(n=45)\end{array}$ \\
\hline Female, n (\%) & $40(88.9)$ \\
\hline $\begin{array}{l}\text { Age at first renal biopsy, median (IQR) } \\
\text { years }\end{array}$ & $29.6(17.1)$ \\
\hline $\begin{array}{l}\text { Fulfilment of ACR } 1997 \text { lupus criteria, }{ }^{10} \\
n(\%)\end{array}$ & 37 (82.2) \\
\hline $\begin{array}{l}\text { Fulfilment of SLICC } 2012 \text { lupus } \\
\text { criteria, }{ }^{11} \mathrm{n}(\%)\end{array}$ & $45(100)$ \\
\hline ANA positive, $n(\%)$ & $42(93.3)$ \\
\hline Sm antibody positive, $n$ (\%) & $12(26.7)$ \\
\hline Anti-dsDNA antibodies positive, $n(\%)^{\star}$ & $29(64.4)$ \\
\hline $\begin{array}{l}\text { Antiphospholipid antibodies positive, } \\
n(\%) * *\end{array}$ & 15 (33.3) \\
\hline $\begin{array}{l}\text { Time between first and second renal } \\
\text { biopsy, median (IQR) years }\end{array}$ & $3.4(4.4)$ \\
\hline Follow-up, median (IQR) years & $8.7(7.5)$ \\
\hline \multicolumn{2}{|c|}{$\begin{array}{l}\text { *and }{ }^{*} \text { : insufficient data from } 4 \text { and } 3 \text { patients, respectively. } \\
\text { ACR, American College of Rheumatology; ANA, antinuclear } \\
\text { antibodies; anti-dsDNA antibodies, antidouble-stranded DNA } \\
\text { antibody; SLICC, The Systemic Lupus International Collaborating } \\
\text { Clinics; Sm, anti-Smith antibodies. }\end{array}$} \\
\hline
\end{tabular}

Sixty-two repeat biopsies $(87.3 \%)$ led to a change in treatment. The choices of treatment regimens were up to the individual nephrologist and rheumatologist. Treatments more frequently used for induction were cyclophosphamide ( $\geq 6$ pulses in $34.3 \%$ and less than 6 pulses in $13.3 \%)$, mycophenolate $(25.7 \%)$ and rituximab $(5.7 \%)$. For maintenance, the more frequently used drugs were mycophenolate $(58.7 \%)$, azathioprine $(20.7 \%)$ and cyclophosphamide $(9.8 \%)$.

At the end of the follow-up, seven patients were in dialysis and other four patients had duplicated their serum creatinine. This subgroup with adverse renal outcome represented $24.4 \%$ of this cohort. Characteristics of second renal biopsy in this subgroup are shown in table 4 . Median time to enter dialysis was 4.4 years (IQR 5.9) since first renal biopsy. Three patients died during follow-up,
Table 3 Class changes in rebiopsies

\begin{tabular}{lll}
\hline Initial biopsy & $\begin{array}{l}\text { Rebiopsies with class } \\
\text { change }(\mathbf{n}=39)\end{array}$ \\
\hline Class II & Class III & 1 \\
& Class IV & 2 \\
Class III & Class V & 2 \\
Class IV & Class IV & 5 \\
& Class VI & 1 \\
& Class II & 2 \\
& Class III & 3 \\
Class V & Class V & 5 \\
& Class III/IV+V & 3 \\
Class III/IV+V & Class VI & 3 \\
Vasculopathy (APS) & Class IV & 4 \\
Unknown Class & Class III/IV+V & 3 \\
\hline APS, antiphospholipid syndrome. & Class IV & 3 \\
& Class IV & 1 \\
& Class VI & 1 \\
\hline
\end{tabular}

causes of deaths were ischaemic colitis, acute abdominal pain and infectious endocarditis. Five of the patients that entered dialysis had a class VI biopsy before and two had a class IV biopsy as the last one.

Median creatinine values at time of second biopsy were significantly higher in patients who had an adverse renal outcome $(2.56 \mathrm{mg} / \mathrm{dL}$ (IQR: $1.7-3.64)$ vs $0.8 \mathrm{mg} /$ $\mathrm{dL}$ (IQR: 0.7-1.03); $\mathrm{p}<0.0001)$. When performing a ROC curve using creatinine at the second biopsy to predict adverse renal outcome, the area under ROC curve was 0.986 (95\% CI 0.957 to $1, \mathrm{p}=0.015)$. A cut-off value of creatinine greater than or equal to $1.3 \mathrm{mg} / \mathrm{dL}$ had $100 \%$ sensitivity and $93.7 \%$ specificity for adverse renal outcome. In a similar way, mean chronicity index at the second biopsy (data missing from 12 patients) was significantly higher in patients with poor renal outcome $(6.6 \pm 1.6$ vs $2.9 \pm 1.7 ; \mathrm{p}<0.0001)$. Area under ROC curve for adverse renal outcome was 0.937 (95\% CI 0.817 to 1, $\mathrm{p}=0.06$ ) and a chronicity index greater than or equal to 6.5 had $87.5 \%$ sensibility and $100 \%$ specificity for that outcome.

Table 2 Classification of first and successive renal biopsies according to the International Society of Nephrology/Renal Pathology Society (ISN/RPS) 2003 classification of lupus nephritis ${ }^{15}$

\begin{tabular}{|c|c|c|c|c|c|}
\hline $\begin{array}{l}\text { Lupus nephritis } \\
\text { classification }\end{array}$ & $\begin{array}{l}\text { 1st biopsy } \\
(n=45)\end{array}$ & $\begin{array}{l}\text { 2nd biopsy } \\
(n=45)\end{array}$ & $\begin{array}{l}\text { 3rd biopsy } \\
(n=18)\end{array}$ & $\begin{array}{l}\text { 4th biopsy } \\
(n=7)\end{array}$ & $\begin{array}{l}\text { 5th biopsy } \\
(n=1)\end{array}$ \\
\hline Class II, n & 5 & 3 & 0 & 0 & 0 \\
\hline Class III, n & 4 & 2 & 2 & 0 & 1 \\
\hline Class IV, n & 22 & 25 & 6 & 4 & 0 \\
\hline Class V, $\mathrm{n}$ & 7 & 8 & 3 & 1 & 0 \\
\hline Class VI, n & 0 & 2 & 2 & 1 & 0 \\
\hline $\begin{array}{l}\text { Combination between III/IV } \\
+\mathrm{V}, \mathrm{n}\end{array}$ & 1 & 3 & 5 & 1 & 0 \\
\hline Vasculopathy, n & 1 & 0 & 0 & 0 & 0 \\
\hline Unknown, n & 5 & 2 & 0 & 0 & 0 \\
\hline
\end{tabular}


Table 4 Characteristics of the second renal biopsy in patients with duplication of creatinine and/or end stage renal disease at the end of follow-up

\begin{tabular}{|c|c|c|c|c|c|c|c|}
\hline & $\begin{array}{l}\text { Class in 1st } \\
\text { biopsy }\end{array}$ & $\begin{array}{l}\text { Age at } \\
\text { 2nd } \\
\text { biospy }\end{array}$ & $\begin{array}{l}\text { Class in } \\
\text { 2nd } \\
\text { biopsy }\end{array}$ & $\begin{array}{l}\text { Activity } \\
\text { index (0-24) } \\
\text { (2nd biopsy) }\end{array}$ & $\begin{array}{l}\text { Chronicity } \\
\text { index (0-12) } \\
\text { (2nd biopsy) }\end{array}$ & $\begin{array}{l}\text { Creatinine at the } \\
\text { time of } 2 \mathrm{nd} \\
\text { biopsy }(\mathrm{mg} / \mathrm{dL})\end{array}$ & $\begin{array}{l}\text { Renal outcome } \\
\text { at the end of } \\
\text { follow-up }\end{array}$ \\
\hline $\begin{array}{l}\text { Patient } \\
1\end{array}$ & IV & 64 & VI & 2 & 8 & 1.6 & $\begin{array}{l}\text { Duplication of } \\
\text { creatinine }\end{array}$ \\
\hline $\begin{array}{l}\text { Patient } \\
2\end{array}$ & $\begin{array}{l}\text { Vasculopathy } \\
\text { (APL) }\end{array}$ & 22 & IV & 0 & 10 & 2.9 & Dialysis \\
\hline $\begin{array}{l}\text { Patient } \\
3\end{array}$ & $\mathrm{~V}$ & 31 & IV & 6 & 7 & 3.1 & Dialysis \\
\hline $\begin{array}{l}\text { Patient } \\
4\end{array}$ & IV & 31 & IV & 2 & 7 & 1.7 & $\begin{array}{l}\text { Duplication of } \\
\text { creatinine }\end{array}$ \\
\hline $\begin{array}{l}\text { Patient } \\
5\end{array}$ & IV & 44 & IV & 5 & 7 & 1.4 & $\begin{array}{l}\text { Dialysis/renal } \\
\text { transplant }\end{array}$ \\
\hline $\begin{array}{l}\text { Patient } \\
6\end{array}$ & IV & 48 & IV & 7 & 7 & 4.6 & $\begin{array}{l}\text { Duplication of } \\
\text { creatinine }\end{array}$ \\
\hline $\begin{array}{l}\text { Patient } \\
7\end{array}$ & unknown & 34 & III & 5 & 7 & 2.6 & Dialysis \\
\hline $\begin{array}{l}\text { Patient } \\
8\end{array}$ & V & 41 & V & 0 & 3 & 2.2 & Dialysis \\
\hline $\begin{array}{l}\text { Patient } \\
9\end{array}$ & IV & 50 & VI & NR & NR & 3.6 & Dialysis \\
\hline $\begin{array}{l}\text { Patient } \\
10\end{array}$ & unknown & 28 & IV & NR & NR & 2.5 & $\begin{array}{l}\text { Duplication of } \\
\text { creatinine }\end{array}$ \\
\hline $\begin{array}{l}\text { Patient } \\
11\end{array}$ & $\mathrm{~V}$ & 45 & V & NR & NR & 2.1 & $\begin{array}{l}\text { Dialysis/renal } \\
\text { transplant }\end{array}$ \\
\hline
\end{tabular}

In multivariable Cox analysis, after adjusting by age at time of second biopsy and activity index, creatinine levels and chronicity index were still associated with poor renal outcome (HR: 1.14 (95\% CI 1.01 to 1.29$)$, and 1.58 (95\% CI 1.1 to 2.3 ), respectively).

\section{DISCUSSION}

The objective of this retrospective study was to analyse the value of repeat renal biopsy in patients with $\mathrm{LN}$ flares. Flares represent a significant problem because of the potential for cumulative damage that may lead to deterioration of renal function as well as toxicity due to additional immunosuppression. ${ }^{17}$ There is enough evidence showing that relapsing nephritis has a worse renal prognosis. 418

Clinical expression of renal flares differs. Some authors have postulated that nephritic flares (mainly when having an active urine sediment, proteinuria greater than $2 \mathrm{~g}$ /day and worsening of renal function) are more important than nephrotic flares (characterised only by proteinuria greater than $2 \mathrm{~g}$ /day). ${ }^{17}{ }^{18}$ However, no clinical or biological feature uniformly predicts renal morphology, particularly the extent of renal lesions. ${ }^{6}$ Moreover, the histological picture in a patient with impaired renal function is unpredictable. ${ }^{6}$

Relapse in LN has been reported in different studies from $27 \%$ to $66 \%$, depending on patients' characteristics, treatments and definitions of flare used in each cohort. ${ }^{17}$
Histological transformation from one class to another is very well recognised in LN, and it can be observed in 49$75 \%$ of repeat biopsies. ${ }^{2} 71920$ Nevertheless, value of a second renal biopsy has been disputed. ${ }^{7} 17$

There are two possible scenarios for repeat renal biopsy: (1) as a strategy for assessing response after induction or maintenance treatment. In these cases, the objective is to evaluate histological markers that may indicate efficacy of the treatment received and/or may predict patient's renal course. ${ }^{3} 4$ (2) on the other hand, some authors have suggested repeat biopsies on clinical indications only, mainly when suspecting a relapse. 1256

Some guidelines suggest a repeat renal biopsy when clinical response to treatment is not as good as expected, in case of flare or if suspecting a histological transformation, ${ }^{21}$ and some others only when anticipating a therapeutic change after the repeat biopsy. ${ }^{22} 23$

In the last few years, prognosis and treatment of histological class III and IV has been homologated, leading to guidelines that do not differentiate the treatment of class III and IV LN. ${ }^{21}{ }^{23-29}$ Considering this, some authors have suggested that transitions between proliferative classes have no additive value on treatment decisions $^{7}{ }^{17}$ and they suggest that when a patient with proliferative lesions on a previous biopsy presents with a renal flare, appropriate induction treatment can be initiated without additional biopsies, since a repeat biopsy will show similar lesions in most cases. ${ }^{7}$ 
In our cohort, histological transformations were common $(54.9 \%)$ in agreement with previous reports, and frequencies of changes were similar between those with proliferative and non-proliferative lesions on the previous biopsy (55.6\% and 58.3\%, respectively, $\mathrm{p}=1$ ). However, when having a previous biopsy with a proliferative lesion, class switch happened in $55.6 \%$, with $24.4 \%$ transforming into non-proliferative classes. This finding differs from the study by Daleboudt $e t a l,{ }^{7}$ mentioned above.

When previous biopsy was class $\mathrm{V}$, transition to other classes occurred in $58.3 \%$ and changes were all into proliferative classes. Only $11.3 \%$ of repeat biopsies showed conversion from one pure proliferative form to another (class III to class IV or vice versa). This is lower than in other cohorts. $^{27}$

In conclusion, and differing slightly from other previous reports, histological switch happened in nonproliferative classes as well as in proliferative ones, with a higher proportion of changes from non-proliferative to proliferative $(58.3 \%$ vs $24.4 \%$, $\mathrm{p}=0.04)$.

Regarding our patients' renal outcomes, they do not differ from previous reports in $\mathrm{LN}$ repeat biopsy studies. $^{2}$ A quarter of the patients had a poor renal outcome, seven patients with end-stage renal disease and other four with serum creatinine duplication; three patients died. When predictors were analysed, having a higher serum creatinine and a higher chronicity index at the second biopsy was associated with poor renal prognosis. These results are in conformity with what has been previously found by authors who have analysed clinical parameters and repeat biopsy parameters to predict renal prognosis. ${ }^{1} 29$

Several limitations of the present study need to be addressed. Our study had a small sample size and we have missing data. Twelve of the biopsies were performed at other hospitals. We do not have the results of some, and in others we only know the class but we could not have access to the histopathological material. Of the biopsies (104) performed at our hospital, not all of them were evaluated with activity and chronicity indices, and they were analysed by different pathologists with different classifications according to the year when they were performed, as mentioned above. We were not able to compare activity and chronicity indices in successive biopsies, analysis that would have been interesting in order to assess efficacy of treatments and prognosis.

There is a reluctance to repeat an invasive procedure with potential complications, but taking into account immunosuppressive treatments' side effects, when a renal flare occurs, it seems reasonable to try to assess kidney impact with accuracy in order to adjust medications to each individual patient. Facing the impossibility of predicting histological changes based on clinical data, performing a repeat renal biopsy appears as a reasonable option. In our patients, rebiopsies were an important guide for treating physicians, since $87.3 \%$ conducted to a treatment change. These modifications included stopping immunosuppressive treatments when biopsies showed a class VI LN.

\section{CONCLUSIONS}

In our cohort, histological transformations were common in successive biopsies (54.9\%). Coming from a previous biopsy with non-proliferative lesions, transformations into proliferative occurred in $58.3 \%$. On the other hand, $24.4 \%$ of the initial proliferative biopsies changed into non-proliferative in the repeat biopsy. We believe, that in renal flares, our experience confirms that repeat renal biopsy allows for more precise therapeutic decisions and better establishing of long-term prognosis in the individual patient.

Contributors All authors made substantial contribution to the following: conception and design, acquisition of data or analysis and interpretation of data; drafting the article or revising it critically for important intellectual content; final approval of the version published.

Competing interests None.

Ethics approval CEPI.

Data sharing statement No additional data are available.

Open Access This is an Open Access article distributed in accordance with the Creative Commons Attribution Non Commercial (CC BY-NC 3.0) license, which permits others to distribute, remix, adapt, build upon this work noncommercially, and license their derivative works on different terms, provided the original work is properly cited and the use is non-commercial. See: http:// creativecommons.org/licenses/by-nc/3.0/

\section{REFERENCES}

1. Esdaile JM, Joseph L, MacKenzie T, et al. The pathogenesis and prognosis of lupus nephritis: information from repeat renal biopsy. Semin Arthritis Rheum 1993;23:135-48.

2. Moroni G, Pasquali S, Quaglini S, et al. Clinical and prognostic value of serial renal biopsies in lupus nephritis. Am J Kidney Dis 1999;34:530-9.

3. Alsuwaida A, Husain S, Alghonaim M, et al. Strategy for second kidney biopsy in patients with lupus nephritis. Nephrol Dial Transplant 2012;27:1472-8.

4. Hill GS, Delahousse M, Nochy D, et al. Predictive power of the second renal biopsy in lupus nephritis: significance of macrophages. Kidney Int 2001;59:304-16.

5. Bihl GR, Petri M, Fine DM. Kidney biopsy in lupus nephritis: look before you leap. Nephrol Dial Transplant 2006;21:1749-52.

6. Ponticelli C, Moroni G. Renal biopsy in lupus nephritis-what for when and how often? Nephrol Dial Transplant 1998;13:2452-4.

7. Daleboudt GMN, Bajema IM, Goemaere NNT, et al. The clinical relevance of a repeat biopsy in lupus nephritis flares. Nephrol Dial Transplant 2009;24:3712-17.

8. Hill GS, Delahousse M, Nochy D, et al. Outcome of relapse in lupus nephritis: roles of reversal of renal fibrosis and response of inflammation to therapy. Kidney Int 2002;61:2176-86.

9. Mosca M, Pasquariello A, Tavoni A, et al. Predictors of renal outcome in diffuse proliferative glomerulonephritis in systemic lupus erythematosus. Lupus 1997;6:371-8.

10. Hochberg M. Updating the American College of Rheumatology revised criteria for the classification of systemic lupus erythematosus. Arthritis Rheum 1997;40:1725.

11. Petri M, Orbai A-M, Alarcón GS, et al. Derivation and validation of the Systemic Lupus International Collaborating Clinics classification criteria for systemic lupus erythematosus. Arthritis Rheum 2012;64:2677-86.

12. Pengo V, Tripodi A, Reber G, et al. Update of the guidelines for lupus anticoagulant detection. Subcommittee on Lupus Anticoagulant/Antiphospholipid Antibody of the Scientific and Standardisation Committee of the International Society on Thrombosis and Haemostasis. J Thromb Haemost 2009;7:1737-40.

13. Miyakis S, Lockshin MD, Atsumi T, et al. International consensus statement on an update of the classification criteria for definite antiphospholipid syndrome (APS). J Thromb Haemost 2006;4:295-306.

14. Golbus J, McCune WJ. Lupus nephritis. Classification, prognosis immunopathogenesis, and treatment. Rheum Dis Clin North Am 1994;20:213-42. 
15. Weening JJ, D'Agati VD, Schwartz MM, et al. The classification of glomerulonephritis in systemic lupus erythematosus revisited. Kidney Int 2004;65:521-30.

16. Austin HA, Muenz LR, Joyce KM, et al. Prognostic factors in lupus nephritis. Contribution of renal histologic data. Am J Med 1983;75:382-91.

17. Sidiropoulos PI, Kritikos HD, Boumpas DT. Lupus nephritis flares. Lupus 2005;14:49-52.

18. Moroni G, Quaglini S, Maccario M, et al. "Nephritic flares" are predictors of bad long-term renal outcome in lupus nephritis. Kidney Int 1996;50:2047-53.

19. Wang G-B, Xu Z-J, Liu H-F, et al. Changes in pathological pattern and treatment regimens based on repeat renal biopsy in lupus nephritis. Chin Med J (Engl) 2012;125:2890-4.

20. Lu J, Tam L-S, Lai FM-M, et al. Repeat renal biopsy in lupus nephritis: a change in histological pattern is common. Am J Nephrol 2011;34:220-5.

21. Kdigo G. KDIGO clinical practice guideline for glomerulonephritis. Kidney Int 2012;2:139-274.

22. Ruiz Irastorza G, Espinosa G, Frutos MA, et al. Diagnosis and treatment of lupus nephritis. Consensus document from the systemic auto-immune disease group (GEAS) of the Spanish Society of Internal Medicine (SEMI) and Spanish Society of Nephrology (S.E.N.). Nefrologia 2012;32(Suppl 1):1-35.
23. Van Tellingen A, Voskuyl AE, Vervloet MG, et al. Dutch guidelines for diagnosis and therapy of proliferative lupus nephritis. Neth $\mathrm{J}$ Med 2012;70:199-207.

24. Radhakrishnan J, Cattran DC. The KDIGO practice guideline on glomerulonephritis: reading between the (guide)lines-application to the individual patient. Kidney Int 2012;82:840-56.

25. Isenberg D, Appel GB, Contreras G, et al. Influence of race/ethnicity on response to lupus nephritis treatment: the ALMS study. Rheumatology (Oxford) 2010;49:128-40.

26. Rovin BH, Furie R, Latinis K, et al. Efficacy and safety of rituximab in patients with active proliferative lupus nephritis: the Lupus Nephritis Assessment with Rituximab study. Arthritis Rheum 2012; 64:1215-26.

27. Ginzler EM, Dooley MA, Aranow C, et al. Mycophenolate mofetil or intravenous cyclophosphamide for lupus nephritis. $N$ Engl J Med 2005;353:2219-28.

28. Contreras G, Pardo V, Leclercq B, et al. Sequential therapies for proliferative lupus nephritis. N Engl J Med 2004; 350:971-80.

29. Gordon C, Jayne D, Pusey C, et al. European consensus statement on the terminology used in the management of lupus glomerulonephritis. Lupus 2009;18:257-63. 